\title{
Structural verification and manufacturing procedures of the cooling system, for DEMO divertor target (OVT)
}

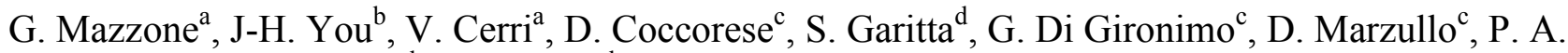 \\ Di Maio ${ }^{\mathrm{d}}$, E. Vallone ${ }^{\mathrm{d}}$, A. Tincani ${ }^{\mathrm{e}}, \mathrm{U}$. Bonavolontà ${ }^{\mathrm{c}}$, V. Imbriani ${ }^{\mathrm{c}}$ \\ ${ }^{a}$ ENEA Frascati, Fusion \& Technology for Nuclear Safety, via E. Fermi 45, 00044 Frascati, Italy \\ ${ }^{b}$ Max Planck Institute of Plasma Physics, Boltzmann Str. 2, 85748 Garching, Germany \\ ${ }^{c}$ CREATE/University of Naples, Industrial Engineering, Piazzale Tecchio 80, 80125 Napoli, Italy \\ ${ }^{d}$ University of Palermo, Department of Energy, Information Engineering and Mathematical Models, Viale delle Scienze, \\ 90128 Edificio 6, Palermo, Italy \\ ${ }^{e}$ ENEA CR Brasimone, 40032 Camugnano (BO), Italy
}

\begin{abstract}
The paper presents the design activities and testing plan of a vertical target mock-up, developed within the pre-conceptual design phase for DEMO Work Package DIV-1 "Divertor Cassette Design and Integration" - EUROfusion Power Plant Physics \& Technology (PPPT) program.

Activities concerning the Divertor Outboard Vertical Target cooling mock-up are presented in term of CAD model, thermal-hydraulic numerical simulation, structural analysis, structural integrity verification and manufacturing procedure. Moreover, the mechanical dimensions of support systems for Plasma Facing Components (PFCs), manifold and diffuser have been analyzed in detail, in order to avoid structural fault during the test.

Test procedures are discussed, taking into account design parameters, design code and facility performances. The CuCrZr alloy selected for the PFCs of EU DEMO divertor has been used also for the mock-up ,while two options are still under evaluation for manifolds/diffuser, $\mathrm{CuCrZr}$ and stainless Steel 316L(N)-IG, depending on the joining technology. Since the mock-up is mainly intended to verify hydraulic performances, it has been simplified by removing the $\mathrm{W}$ monoblocks from its PFCs.
\end{abstract}

Keywords: DEMO, divertor cassette, divertor target cooling mock-up.

\section{Introduction}

In the frame of the EU fusion roadmap activity Horizon 2020 [1] the pre-conceptual design activity of Demonstration Fusion Power Reactor (DEMO) has been launched by the EUROfusion Consortium. One of the main in vessel components is the divertor cassette and related plasma facing components. The main details can be found in [2][3].

\section{Design activity for Divertor Integration}

A design activity for DEMO divertor has been performed in the last two years. Fig.1 shows the DEMO divertor assembly with the main components: the Cassette, Outer Vertical Target (OVT), Inner Vertical target (IVT), Liner, cooling tubes and Divertor-VV mechanical connections.

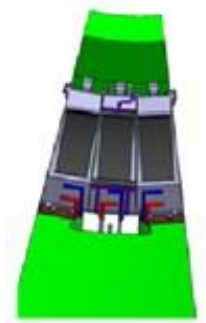

a

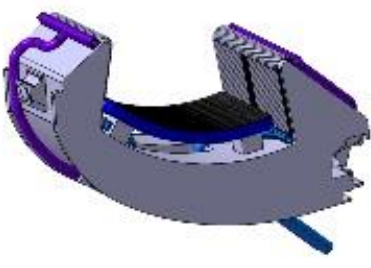

b
Fig.1 - DEMO divertor assembly. a) For each DEMO lower port 3 divertor cassette will be inserted in the machine; b) $3 d$ view of divertor Central cassette
The OVT has been selected for the mock-up test. The first step was to prepare a detailed CAD model as illustrated in Fig.2. The OVT Mock-up cooling circuit has the same structure of the corresponding VT. It has also been conceived taking into account the presence of swirl tapes inside PFU channels (Plasma Facing Unit). Small differences might be noticed in the conformation of the diffuser and the horizontal headers, mainly due to manufacturing constraints (see Section 5 Manufacturing ) .

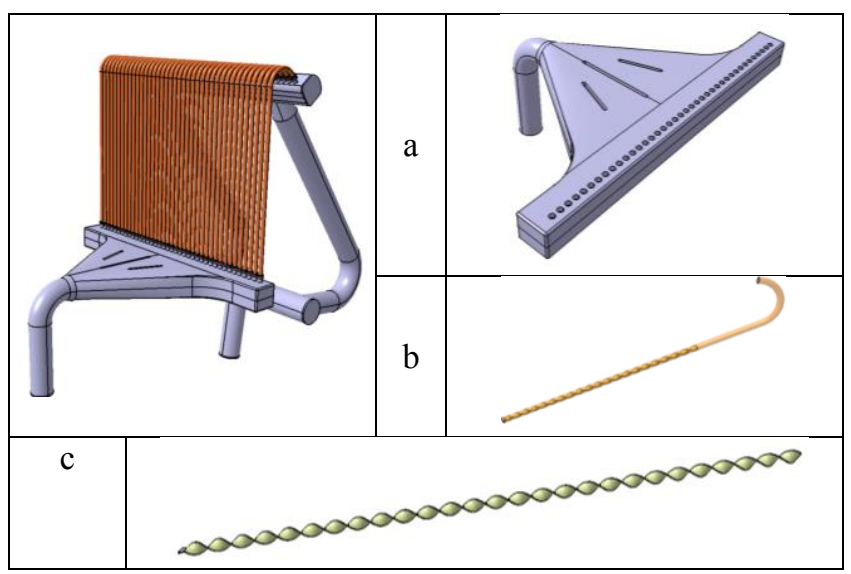

Fig.2 - CAD model of OVT Mock-up: a) Diffuser, b) PFU c) Swirl Tapes. 


\section{Thermo Hydraulic calculation}

The thermal-hydraulic performances of the OVT Mock-up to be tested at ENEA-labs have been assessed under four different operative conditions, namely reference, alternative, room and CEF (Circuiti per Esperienze di Fluidodinamica) conditions (see Table 1), mainly in order to check whether they might be considered as representatives of those numerically predicted for the DEMO Divertor PFCs cooling circuit and widely reported and discussed in [4], [5] and [6].

Table 1. OVT Mock-up Cooling conditions (CEF values are the facility parameters).

\begin{tabular}{|l|c|c|c|c|}
\hline \multicolumn{5}{|c|}{ Summary of coolant Operative Conditions } \\
\hline Parameter & Reference & Alternative & Room & CEF \\
\hline Inlet Pressure $[\mathrm{MPa}]$ & 5.0 & 5.0 & 1.0 & 2.4 \\
\hline Temperature $\left[{ }^{\circ} \mathrm{C}\right]$ & 133 & 95 & 20 & 133 \\
\hline G per OVT $[\mathrm{Kg} / \mathrm{s}]$ & 54.95 & 37.64 & 67.56 & 54.95 \\
\hline
\end{tabular}

The thermal-hydraulic performances of the OVT Mockup cooling circuit have been assessed following a theoretical-numerical approach based on the Finite Volume Method and adopting the ANSYS-CFX v.16.2 commercial Computational Fluid-Dynamic (CFD) code. A detailed description of model, mesh, loads and boundary conditions adopted is reported in [7].

Obtained results have indicated that a total pressure drop of $\sim 0.7 \mathrm{MPa}$ is predicted under reference, room and CEF condition, whilst it amounts to $\sim 0.3 \mathrm{MPa}$ under alternative condition. Moreover, they have clearly confirmed that the OVT Mock-up may be tested at reference, room and CEF conditions to realistically predict the actual OVT hydraulic behavior, mainly in terms of pressure drop and coolant velocity and mass flow rate distribution within PFU cooling channels.

\section{Experimental Test Matrix}

Taking into account the OVT thermal-hydraulic requirements and the facility parameter (see chapter 7 CEF1 Experimental Facility) the following tests will be performed:

-Cold Water Flow Test: The first test requires that the prototype is flow tested at $20^{\circ} \mathrm{C}$ and $2.4 \mathrm{MPa}$.

-Hot Water Flow Test: The second test requires that the prototype is flow tested with a temperature that gradually reaches $130^{\circ} \mathrm{C}$ and $\mathrm{p}=2.4 \mathrm{MPa}$. Possible test matrixes for the steady state tests have been summarized in Table 2. The run 1-4 are the Cold Water Flow Test.

Table 2. Test matrix for OVT mock-up

\begin{tabular}{|c|c|c|c|c|c|}
\hline Run & Temperature & \multicolumn{4}{|c|}{ Flow Rate } \\
\hline$\left[\mathrm{N}^{\circ}\right]$ & {$\left[\mathrm{C}^{\circ}\right]$} & \multicolumn{4}{|c|}{]} \\
\hline $1-4$ & 20 & 15 & 25 & 35 & 55 \\
\hline $5-8$ & 70 & 15 & 25 & 35 & 55 \\
\hline $9-12$ & 100 & 15 & 25 & 35 & 55 \\
\hline $13-16$ & 130 & 15 & 25 & 35 & 55 \\
\hline
\end{tabular}

-Cold hydrostatic Water Test: Hydrostatic pressure test at $7.15 \mathrm{MPa}$ and $20{ }^{\circ} \mathrm{C}$ will be carried out in order to:

a) Verify the mechanical resistance of the components; b) Measure displacements of the mock-up components under pressure loads.

\section{Manufacturing procedures}

Starting from the CAD model used for thermalhydraulic calculation in Fig. 2 a detailed study of manufacturing and welding procedure has been done for the main mock-up components. Also a support system has been integrated in the final design of the mock-up. Fig. 3 shows the final CAD model, ready for manufacturing.

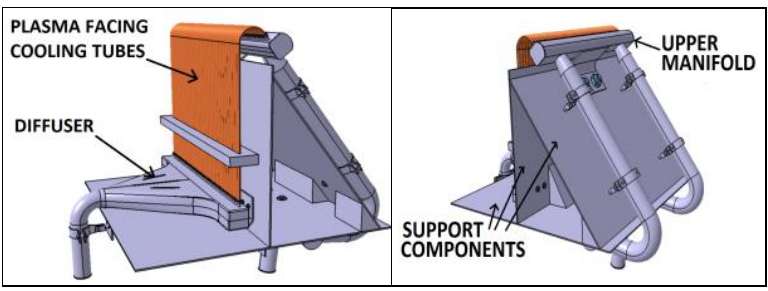

Fig. 3 - Mock-up CAD model ready for manufacturing.

The main components are:

- The PF (Plasma Facing) cooling tubes consisting of 39 tubes in $\mathrm{CuCrZr}$ with external diameters of $15 \mathrm{~mm}$ and internal diameter of $12 \mathrm{~mm}$, the length of the straight part is $625.5 \mathrm{~mm}$. The tubes have an internal helical swirl tape with a pitch four times the diameter $(48 \mathrm{~mm})$ and a thickness of $0.8 \mathrm{~mm}$. It will be made of Copper and it will be $500 \mathrm{~mm}$ long.

- $\quad$ The Upper Manifold made in AISI-316L steel, it consists of two halves welded together by means of a TIG-welding (see Fig. 4). The use of two parts allows us to weld the transition joints inside the manifold, avoiding the external problem of lack of operating space due to the proximity of different PFUs.

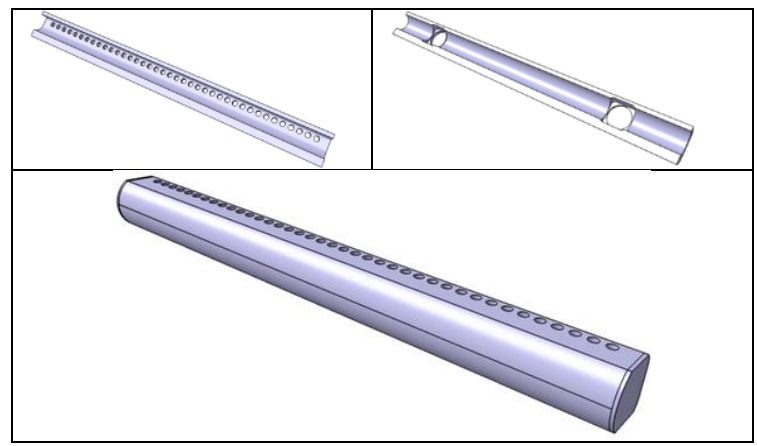

Fig. 4 Upper manifolds

- The Diffuser made in AISI-316L(N). The geometry of this component is rather complicate; it was therefore thought to obtain the diffuser and the inlet manifold from a single block of steel. It is made of an upper part and a lower part to be subsequently welded (Fig. 5). The diffuser has three internal ribs for structural integrity. Fluid-dynamic calculations [5] show that no important changes in terms of coolant flow rate into the $\mathrm{CuCrZr}$ lateral tubes are expected. 


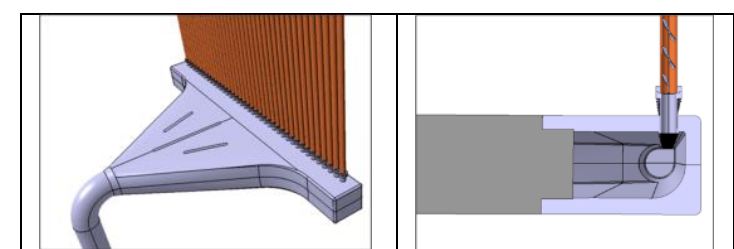

Fig. 5 Diffuser

The Transition CuCrZr /AISI 316 tubes, i.e. the connection between the PFCs $\mathrm{CuCrZr}$ tubes and manifold/Diffuser AISI 316 for which two procedures have been tested: a) Hot Radial Pressing (HRP) in vacuum with $\mathrm{Cu}$ interlayer -temperature $600^{\circ} \mathrm{C}$ and internal pressure $\sim 600$ bar; b) Brazing in air with the use of the Lastek 31 silver alloy as filler material (Fig. 6). Both procedures have passed first pressure test with Helium at $p \sim 70$ bars and temperature of $\sim 25^{\circ} \mathrm{C}$. For the reason of economy with respect to HRP it has been decided to use the brazing in air procedure for the scope of the mockup. In the final OVT for DEMO, HRP will be used because it is the only procedure permitted under high vacuum condition.

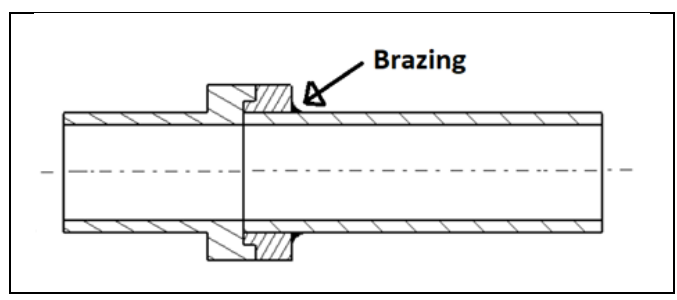

Fig. 6 Transition CuCrZr /AISI 316 tubes Brazing in air.

- $\quad$ The Support components consisting of three aluminum plates (Fig. 7), Flexible Supports (Fig. 8) and Small support plates (Fig. 9).

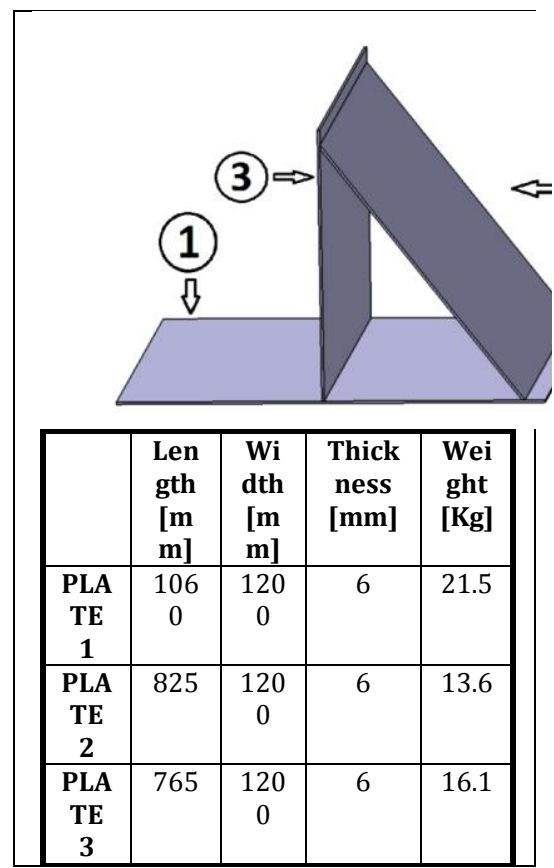

Fig. 7 Assembly aluminium plates

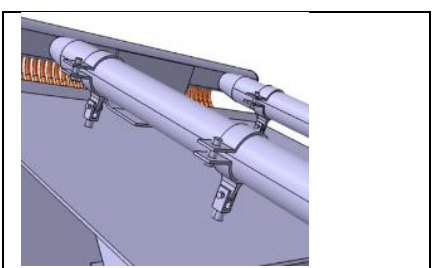

Fig. 8 Flexible support integrate on Mock-Up

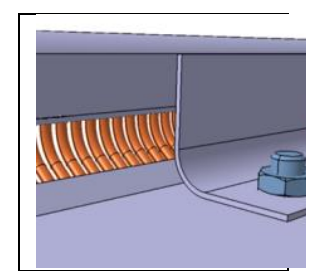

Fig. 9 Small support plates
6. Structural verification

Structural analyses have been performed on the OVT Mock-up, given the simultaneous occurrence of primary membrane stresses in the entire model and high bending stresses due to the coolant pressure on inboard wall. A survey of all options within the design rules was required to identify the inter-dependencies of the individual stress limits.

According to [8] two different type of damage shall be evaluated to prove the structural integrity of OVT Mockup:

- $\quad$ Primary $(\mathrm{P})$ type damage

- $\quad$ Secondary (S) type damage

The elastic analysis method has been used to check the rules for prevention of both types of damage. The rules applied to prevent both of them are compliant to Level A criteria, in case of negligible creep and negligible irradiation.

The aim of level A criteria [7] is to protect the component from the following types of damage:

- immediate or time-dependent excessive deformation,

- immediate or time-dependent plastic instability,

- time-dependent fracture,

- elastic or elastoplastic instability, immediate or time-dependent,

- progressive deformation,

- fatigue.

According to [9] the allowable stresses are:

AISI 316

CuCrZr (Treatment A)

$\left(\right.$ at $\left.130^{\circ}\right)=130 \mathrm{MPa}$

$\left(\right.$ at $\left.200^{\circ}\right)=130 \mathrm{MPa}$

(Treatment A: solution annealing + cold work + ageing)[8]. Both primary membrane stress and primary membrane + bending stress have been verified according to RB 3251.112[8].

$$
\begin{aligned}
\mathrm{Pm} & <\mathrm{Sm} \\
\mathrm{Pm}+\mathrm{Pb} & <1,5 * \mathrm{Sm}
\end{aligned}
$$

In case it is considered also the action of operative temperature on all bodies, the rules for prevention of secondary damages, according [8] are:

$$
\mathrm{Pm}+\mathrm{Pb}+\mathrm{Q}<3 * \mathrm{Sm}
$$

The operating conditions analyzed are reported in Table 3.

Table 3 - Input of structural analyses.

\begin{tabular}{|c|c|c|}
\hline Operative conditions & $5 \mathrm{MPa}$ & $130^{\circ} \mathrm{C}$ \\
\hline Analysis 1 & $\boldsymbol{}$ & - \\
\hline Analysis 2 & - & $\boldsymbol{\checkmark}$ \\
\hline Analysis 3 & $\boldsymbol{V}$ & $130^{\circ} \mathrm{C}$ \\
\hline Test Conditions & $7.15 \mathrm{MPa}$ & \\
\hline
\end{tabular}




\begin{tabular}{|c|c|c|}
\hline $\begin{array}{c}\text { Analysis 4 } \\
\text { (Hydrostatic Test) }\end{array}$ & $\boldsymbol{V}$ & - \\
\hline
\end{tabular}

The structural integrity verification following the [8] needs the linearization of the stresses along the main paths (rule RB 3324.31). The critical paths have been defined through an elastic analysis applying the most critical load scheme to the structure. In this configuration the Equivalent Von Mises Stress has been evaluated to define the region of the structure subjected to highest stress distribution. Twelve different paths have been identified as critical, their positions are shown in Fig. 10.

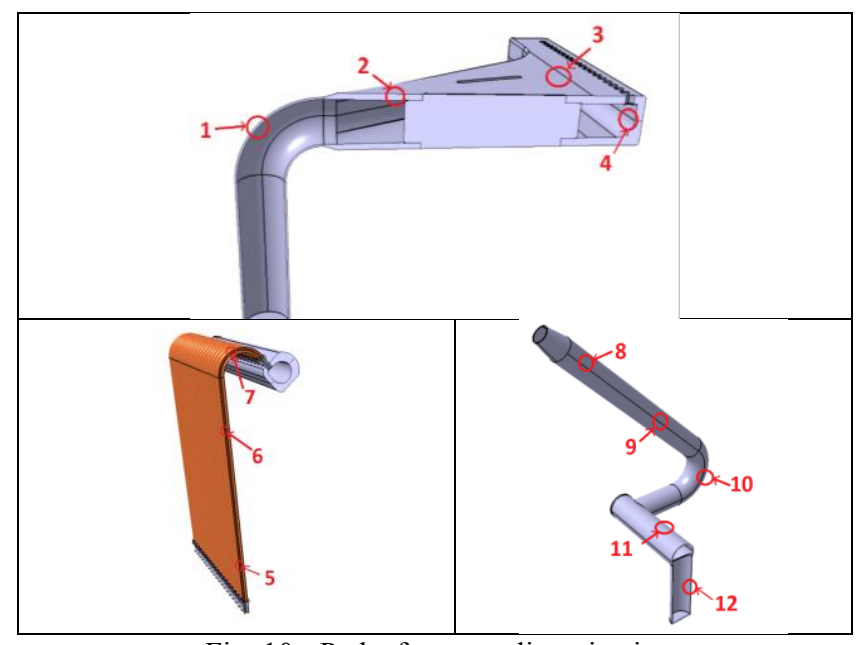

Fig. 10 - Paths for stress linearization

The results in terms of stress and displacement contours have been reported for analysis 4 (Fig.11).

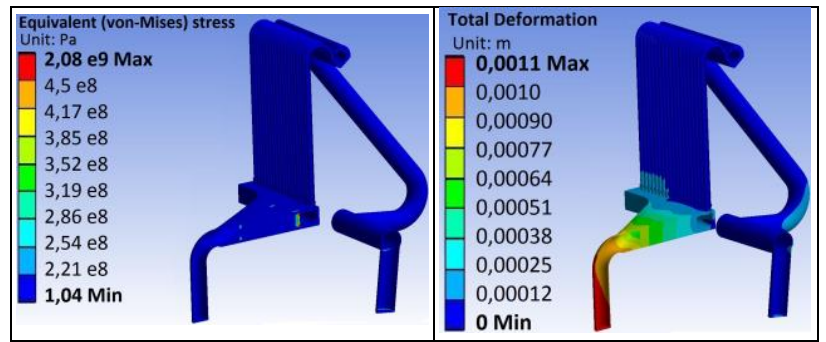

Fig. 11 (a) - Equivalent stress and deformation for Analysis 1 $\left[\mathrm{P}=5 \mathrm{MPa}, \mathrm{T}=20^{\circ}\right]$.

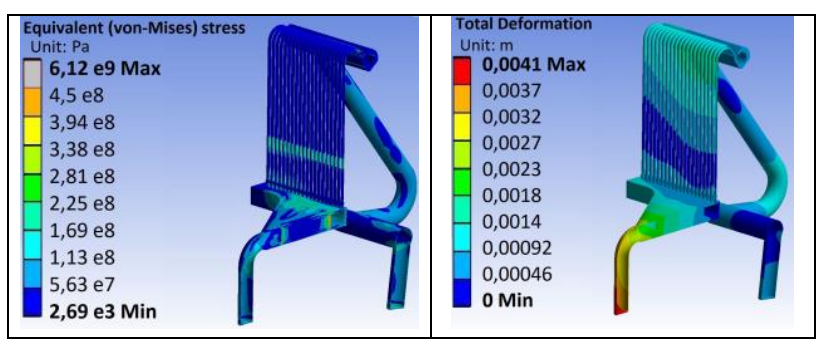

Fig. 12 (b) - Equivalent stress and deformation for Analysis 3 $\left[\mathrm{P}=5 \mathrm{MPa}, \mathrm{T}=130^{\circ}\right]$.

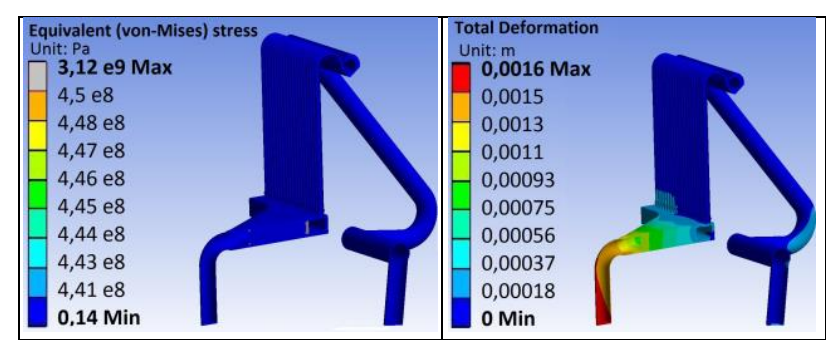

Fig. 13 (c)- Equivalent stress and deformation for Hydrostatic Test $\left[\mathrm{P}=7.5 \mathrm{MPa}, \mathrm{T}=20^{\circ}\right.$ ].

The Fig. 11 shows the analysis carried out to avoid primary and secondary damages, and a hydrostatic test as requested by RCC-MRx [8].

In conclusion for all Mock-up components the stresses are far from the allowable limits (shown in Fig. 11) and shouldn't cause structural problems during operative condition and test phase.

\section{CEF1 Experimental Facility}

The experimental test campaign will be carried out by means of the CEF 1 water loop at ENEA - Brasimone labs [10] and [11] and it will be mainly articulated in steady state tests. The facility consists of a heat exchanger, two centrifugal pumps which can be operated in series or in parallel, the test section and the return line to the pressurized tank Fig. 14. The design parameters are reported in Table 4.

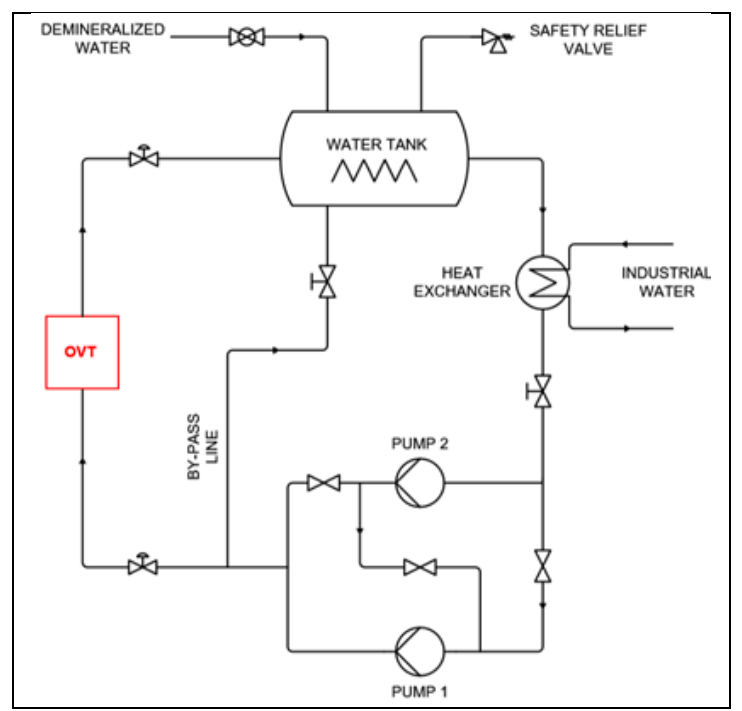

Fig. 14 OVT mock-up integrated in CEF 1

Table 4 CEF design parameters (Note- the Tank is placed in the upper part of the loop, at around 5 meters from ground level, and is designed for 5 bars while the piping downstream the pumping systems, placed under ground level, is designed for $2.5 \mathrm{MPa}$ )

\begin{tabular}{|l|c|}
\hline Parameter & Value \\
\hline Processed fluid & Demineralized water \\
\hline Tank design pressure & $0.5[\mathrm{MPa}]$ \\
\hline Piping design Pressure & $2.5[\mathrm{MPa}]$ \\
\hline Loop design temperature & $140\left[{ }^{\circ} \mathrm{C}\right]$ \\
\hline Pump max. flowrate & $2 \times 70[\mathrm{Kg} / \mathrm{s}]$ \\
\hline Pump max head & $2 \times 1.2[\mathrm{MPa}]$ \\
\hline Electrical heated power & $2 \times 60[\mathrm{KW}]$ \\
\hline
\end{tabular}


Steady state thermal-hydraulic tests will be carried out under the DEMO-relevant range of water temperature (from RT to $130{ }^{\circ} \mathrm{C}$ ) and reduced pressure (up to $2.4 \mathrm{MPa}$ ). During this type of tests, the total pressure drop will be determined as well as the flow-rate distribution in the PFU channels.

The main instrumentation of the experimental set-up, during steady state tests, consists of:

-Two thermocouples, for the measurement of OVT inlet-outlet water temperature;

-A pressure transmitter upstream OVT;

-A Differential pressure transmitter;

-A water flow-meter type Vortex;

-Ultrasonic Flow Meter for measure the flow distribution in the 39 PFUs (see Fig. 15).

Reduction of twisted tape length is important to obtain a reliable measure of flow rate by ultrasonic flow meter. Free length for installation should be around 10 diameters upstream and 5 downstream.

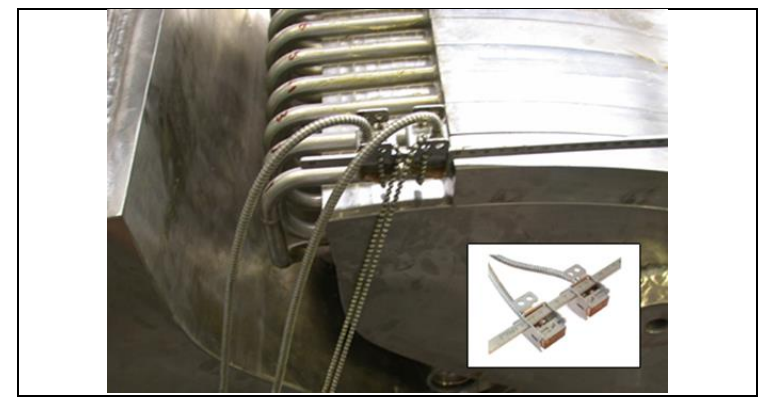

Fig. 15 Ultrasonic Flow Meter type F601 with measurement range $0,01-25 \mathrm{~m} / \mathrm{s}$.

Possible cavitation occurrence has been investigated for: Water at $2.4 \mathrm{MPa}$ and $130{ }^{\circ} \mathrm{C},(54.95 \mathrm{~kg} / \mathrm{s})$.

The cavitation index utilized to estimate this occurrence was defined as:

with:

$$
\sigma=(\mathrm{Ps}-\mathrm{Pv}) / \mathrm{Pd}
$$

-Ps $=$ static pressure in the cavitation zone of the component

$-\mathrm{Pv}=$ vapor pressure in the fluid at operating temperature

$-\mathrm{Pd}=0.5 \rho \mathrm{V}^{2}$ or dynamic pressure in the cavitation zone of the component.

$\rho=$ density of the fluid at operating temperature.

When $\sigma<1$ the probability of cavitation occurrence is high. The first results have shown no cavitation insurgence.

\section{Conclusion}

The main activities about the preparation of a mockup for the verification of the hydraulic performances of the DEMO divertor OVT cooling system have been presented. The design work and preliminary test of transition connection between $\mathrm{CuCrZr}$ and AISI $316 \mathrm{~L}$ tubes have been completed. The mock-up manufacture is ongoing.
At the same time the CEF ENEA facility is under maintenance and update of control system to be ready in the next few months to test the mock-up.

\section{Acknowledgments}

This work has been carried out within the framework of the EUROfusion Consortium and has received funding from the Euratom research and training programme 2014-2018 under grant agreement No 633053. The views and opinions expressed herein do not necessarily reflect those of the European Commission.

\section{References}

[1] F. Romanelli, Fusion Electricity -A roadmap to the realisation of fusion energy, European Fusion Development Agreement (EFDA), 2012 -ISBN 978-3-00040720-8.

[2] J.H. You, G. Mazzone et al., Conceptual design studies for the European DEMO divertor: Rationale and first results, Fusion Engineering and Design, Volumes 109111, Part B, 2016,Pages 1598-1603.

[3] J.H. You, G. Mazzone et al., Progress in the initial design activities for the European DEMO divertor: Subproject "Cassette", Fusion Engineering and Design, Volume 124, 2017, Pages 364-370.

[4] P.A. Di Maio, G. Mazzone et al., Computational thermofluid-dynamic analysis of DEMO divertor cassette body cooling circuit, Fusion Engineering and Design (2018), https://doi.org/10.1016/j.fusengdes.2018.05.063

[5] P.A. Di Maio, G. Mazzone et al., On the thermalhydraulic optimization of DEMO divertor plasma facing components cooling circuit, Fusion Engineering and Design https://doi.org/10.1016/j.fusengdes.2018.05.032

[6] P.A. Di Maio, G. Mazzone et al., Analysis of steady state thermal-hydraulic behaviour of the DEMO divertor cassette body cooling circuit, Fusion Engineering and Design 124 (2017), 437-441.

[7] P. A. Di Maio, S. Garitta, G. Mazzone, E. Vallone, DEMO Divertor - Thermo-hydraulic assessment report 2017, Final Report on Deliverable DIV-1-T004-D007, IDM Ref. N. EFDA_D_2MR3LR.

[8] RCC-MRx code, 2012 edition with 2013 1st Addendum (rule RC 5912.2).

[9] ITER SDC-IC -ITER Structural Design Criteria in-vessel components - Appendix A Materials Design Limit Data.

[10] A. Tincani et al., Steady state and transient thermalhydraulic characterization of full-scale ITER divertor plasma facing components, Fusion Engineering and Design 83 (2008) 1034-1037.

[11] A. Tincani et al., Hydraulic characterization of the full scale divertor cassette prototype, Fusion Engineering and Design 86 (2011) 1673-1676. 